\title{
Using GM to Analyze EST Texts*
}

\author{
JIAO Mei-na, MENG Fan-mao \\ Linyi University, Linyi, China
}

\begin{abstract}
The role of the grammatical metaphor (GM) theory to systemic-functional linguistics (SFL) as well as to metaphor studies has been generally acknowledged. Based on the framework of GM theory in SFL, this thesis, by conducting a statistical analysis of the distribution of 13 types of GM in 20 English for science and technology (EST) texts which are chosen at random and aimed at different readers, is intended, on the one hand, to test and verify the applicability and feasibility of Halliday's grammatical metaphor theory as well as the correctness of Halliday-Martin's claim and on the other, to analyze the reasons for using GM, especially experiential GM substantially in EST texts.
\end{abstract}

Keywords: systemic-functional grammar, grammatical metaphor, EST texts

\section{Introduction}

The systemic-functional approach to GM dates from Halliday, who introduces two perspectives on metaphor: LM (lexical metaphor) and GM. Halliday considers GM as a kind of variation, i.e., the "variation in the expression of a given meaning". He initially classifies GM into two kinds: ideational metaphors and interpersonal metaphors. Later on, he proposes the notion of grammatical metaphor syndrome and classifies GM into 13 types on the basis of this notion. Given that at present the analysis and study of EST texts mostly remain at the experiential or intuitive level, this thesis, based on grammatical metaphor theory, proceeds to analyse GMs in EST texts in the hope of bringing out the characteristics of EST texts and providing theoretical interpretations for the reasons why they come into existence.

Martin realizes that "grammatical metaphor is sensitive to metafunction and it is possible to recognize different types of metaphor according to the kinds of meaning they interface" (Martin, 1992, p. 406), and proposes the notion of textual metaphors. With the focus on the analysis of experiential metaphors, nominalization in particular, this thesis applies 13 types of grammatical metaphors Halliday generalized in 1999 to analyse 20 EST texts which are chosen at random and aimed at the different readers. According to data analysis we find that in EST texts, especially formal and specialized ones, nominalization is the highest in the frequency of occurrence, which further proves Halliday-Martin's claim: In EST texts what we are calling grammatical metaphors is mainly nominalization. By packing clauses into nominal groups, nominalization serves to disguise overt processes, create special texture, and fulfil a certain function in textual cohesion and meanwhile renders the texts more abstract and complex. Therefore, we can resort to nominalization to strengthen the scientific nature of the EST articles or texts in writing them; when reading them, we can unpack

\footnotetext{
* Acknowledgements: This article is sponsored by the program "The Adverse Impact of the Internet on University Students' Learning Behaviors".

JIAO Mei-na, Class 4, Grade 2013, School of Foreign Languages, Linyi University. MENG Fan-mao, professor, master, School of Foreign Languages, Linyi University.
} 
nominalised structures into clauses, thus rendering EST texts less abstract and less complex but more logical and as a result setting to help foreign language learners with a better understanding of EST texts.

Based on Halliday's theoretical framework of GM, this thesis analyses the GMs in EST texts with a view to bringing benefit to language teaching, EST teaching in particular. Besides, the language of science and technology is the tool for reflecting human's cognition and the achievements human beings make in knowing the world and so it is of great value and importance to explore EST texts for us to predict the trend of language development and the law of human cognitive development.

\section{Theories of GM}

\section{Halliday's Approach to GM}

Up to now, the theory of GM under the framework of Halliday's SFL has undergone three major stages in the course of its development: germination, establishment, and expansion. Since 1990s, Halliday has published a series of papers successively, further expounding and developing a few important concepts in his theory of GM. Besides, some other systemic-functionalists each aired their own views, which enriched or expanded the theory of GM from different angles. Among these views, the most important and influential is concerned with Martin's idea of textual metaphor (Martin, 1992).

On the basis of discussions concerning GMS, Halliday classifies GM again and recognizes 13 types of GM as follows:

(1) Quality $\rightarrow$ entity: Epithet $=$ Thing;

(2) Process $\rightarrow$ entity: (i) Event = Thing; (ii) Auxiliary (tense, phase, modality) $=$ Thing;

(3) Circumstance $\rightarrow$ entity: Minor process $\rightarrow$ Thing;

(4) Relater $\rightarrow$ entity: Conjunctive $=$ Thing;

(5) Process $\rightarrow$ quality: (i) Event = Epithet; (ii) Auxiliary (tense phase, modality) = Epithet;

(6) Circumstance $\rightarrow$ quality: (i) Manner = Epithet; (ii) Other = Epithet; (iii) Other = Classifier;

(7) Relater $\rightarrow$ quality: Conjunctive $=$ Epithet;

(8) Circumstance $\rightarrow$ process: Minor process $=$ Process;

(9) Relater $\rightarrow$ circumstance: Conjunctive = Event;

(10) Relater $\rightarrow$ circumstance: Conjunctive $=$ Minor process;

(11) $[$ Zero] $\rightarrow$ entity;

(12) [Zero] $\rightarrow$ process;

(13) Entity $\rightarrow$ [expansion]: Head $=$ Modifier. $^{1}$

For a better understanding of these 13 types of GM, in the following section I will illustrate them one by one: (1) transference from quality to entity, namely transference from adjectives to nouns, e.g., impossible $\rightarrow$ impossibility, safe $\rightarrow$ safety; (2) transference from process to entity, i.e., transference from verbs to nouns, e.g., transform $\rightarrow$ transformation, invent $\rightarrow$ invention; besides, transference from tense, modality, etc., to things is also included into this kind of GM, e.g., will/be going to $\rightarrow$ prospect, can/could $\rightarrow$ possibility, potential; (3) transference from circumstance to entity, i.e., transference from prepositions to nouns, e.g., with $\rightarrow$ accompaniment, to $\rightarrow$ destination; (4) transference from relater to entity, i.e., transference from

\footnotetext{
${ }^{1}$ Notes: In the above table, the arrow " $\rightarrow$ " signals transference; the equal sign "=" indicates the substitution of metaphorical forms for congruent ones; other refers to the circumstantial elements of other types; [zero] is equal to zero person in traditional grammar.
} 
conjunctives to nouns, such as $s o \rightarrow$ cause/proof, if $\rightarrow$ condition; (5) transference from process to quality, for instance, the verb increase can be transferred into an adjective increasing; in addition, some elements indicating tense and modality can be also transferred into adjectives, such as was/used to $\rightarrow$ previous, must/will (always) $\rightarrow$ constant; (6) transference from circumstance to quality, i.e., transference from adverbial or prepositional groups to adjectives, e.g., [decided] hastily $\rightarrow$ hasty [decision], [argued for a long time] $\rightarrow$ lengthy argument, [cracked] on the surface $\rightarrow$ surface [cracks]; (7) transference from relater to quality, i.e., transference from conjunctives to adjectives, i.e., then $\rightarrow$ subsequent, so $\rightarrow$ resulting; (8) transference from circumstance to process, i.e., transference from some prepositions to verbs, e.g., be about $\rightarrow$ concern, be instead of $\rightarrow$ replace; (9) transference from relater to process, i.e., transference from conjunctives to verbs, e.g., then $\rightarrow$ follow, so $\rightarrow$ cause, and $\rightarrow$ complement; (10) transference from relater to circumstance, i.e., transference from conjunctives to prepositions, e.g., when $\rightarrow$ in times of/in...times, if $\rightarrow$ under conditions of/under...conditions; (11) transference from [zero] to entity, such forms of expression as the phenomenon of belong to this type of GM; (12) transference from [zero] to process, e.g., occurs/ensues; and (13) transference from entity to [expansion], i.e., the linguistic phenomenon of the use of nouns as modifying expansion elements, e.g., the government $[$ decided $] \rightarrow$ the government's [decision $],[a$ decision $]$ by the government $\rightarrow[a]$ governmental [decision], etc.

According to the new classification of GM on the part of Halliday, we can find out that his theory of GM has changed in at least three aspects: First, only in terms of its forms of representation in lexicogrammar, ideational grammatical metaphors no longer merely refer to the nominalization, but meanwhile include many other types of transference from verbs to adjectives (inclusive of participles), from prepositions to nouns, from prepositional groups or conjunctives to verbs, etc.

\section{Martin's Treatment of GM}

Following Halliday, Martin also distinguishes congruent metaphorical realizations from incongruent metaphorical realizations. In Martin's opinion, “a congruent relationship is one in which the relation between semantic and grammatical categories is natural: people, places, and things are realized nominally; actions are realized verbally; logical relations of time and consequence are realized conjunctively, and so on" (Martin, 1992, p. 328). By contrast, "Unnatural" relationships are those in which actions are realized as nouns, and logical relations are realized as verbs. Accordingly, all meanings have more than one manner of realization, either congruently or incongruently. GM is the process whereby meanings are multiply-coded at the level of grammar.

Martin is right in recognizing that there exist natural and unnatural relationships between semantic and grammatical categories, but his treatment seems to be primarily concerned with the relationship between semantic and grammatical word classes. Martin's studies on GM are of great value in helping us understand some of the features of GM, such as the multiply-coded meanings of GM, but, unconsciously or deliberately, he fails to give a definition, too.

Although GM has something to do with the three metafunctions of language, there is no one to one relationship between them. The theory of GM attempts to probe into how the lexicogrammatical system of language reshapes human experience and becomes the source for meaning, namely the meaning potential on the basis of analyzing the metaphorical relationship between language and the world. In other words, the theory of $\mathrm{GM}$, is not only a part of the theoretical system of systemic-functional linguistics, and what is more important, 
it reveals Halliday's views on such a linguistic and philosophical proposition as the relation between language and the world, thus imbued with profound linguistic and philosophical implications.

\section{Explorations Into GMs in EST Texts}

Many people, both native speakers and non-native speakers find the language of scientific thought extremely difficult to access, and some educators believe that the language of science acts as a barrier to learning in the field, effectively stopping some children from achieving success in science. Internationally, scientists whose first language is not English often need to read textbooks or research articles published in English, and many of them wish to publish in English. On the other hand, with the world merging into an organic whole, the exchanges among the countries in science and technology are getting increasingly frequent. Against such a background, English, as "the international scientific language", is playing a more and more important role. Therefore, it is of great importance to have a good command of English, English for science and technology in particular for the sake of timely knowing about and following the latest developments in science and technology, popularizing our own advanced or up-to-date achievements in scientific research. Up to now, many universities and colleges in our country have offered EST on their curriculum. Such practical problems of learning and teaching in relation to science have led to a number of investigations into the nature of scientific writing.

Halliday and Martin address the problem from two perspectives: the identification of the particular characteristics of scientific prose and the issues involved in educating children to use and understand language appropriate to specific contexts. In both these tasks, they use aspects of functional grammar to analyze and describe the language and to explain how it develops.

We should, with the aid of the latest theoretical achievements in linguistics and other related disciplines proceed to make a more profound survey of EST texts from various perspectives in expectation of having a thorough grasp and command of the characteristics of EST texts and in turn serving language teaching and learning better. This thesis, in the following sections, will, with the help of the theory of SFL and that of GM, carry out a detailed investigation into the GMs in the three types of EST texts chosen at random and aimed at different readers in the hope of bringing out the features characteristic of EST texts and the rules governing them and offering some functional explanations of them.

\section{A Statistical Analysis of the Distribution of 13 Types of GM in EST Texts}

The corpus for this study involves 20 passages. To ensure the representativeness of the corpus, the passages are randomly chosen almost from all the major disciplines concerning science and technology such as biology, physics, chemistry, medicine, computer, mechanics, ecology, geology, mathematics, aerospace, etc. This thesis first counts the number of each type of GM in EST texts and works out the ratio of each type of GM. The statistical results are as follows:

Table 1

The Number and the Ratio of Each Type of GM in EST Texts

\begin{tabular}{|c|c|c|c|c|c|c|c|c|c|c|c|c|c|c|}
\hline Items & 1 & 2 & 3 & 4 & 5 & 6 & 7 & 8 & 9 & 10 & 11 & 12 & 13 & Total \\
\hline $\mathrm{N}$ & 11 & 75 & 0 & 0 & 28 & 5 & 0 & 0 & 0 & 0 & 0 & 0 & 0 & 119 \\
\hline $\mathrm{P}$ & 9.1 & 63 & 0 & 0 & 23.5 & 4.1 & 0 & 0 & 0 & 0 & 0 & 0 & 0 & 100 \\
\hline
\end{tabular}

Notes. As is shown in Table 1, 1 in the column stands for the first type of EST texts, and likewise, 2 for the second type, and 3 for the third type. $N$ along the horizontal line stands for the number of each type of GM in EST texts, $P$ for the ratio of each type of GM. 
As is shown in the above table, GM of the first type and the second type, namely nominalization, ranks the highest in the frequency of occurrence. This exactly proves Halliday-Martin's claim: In EST texts one of the most important ways in which grammatical metaphor arises is nominalization.

\section{A Functional Analysis of the Reasons for the Use of Experiential GM in EST Texts}

According to Halliday and Matthiessen, a phenomenon is the most general experiential category: anything that can be construed as part of human experience. The phenomena of experience are of three orders of complexity: a single element, a figure, and a sequence. A figure and an element are congruently realized in the grammar by a clause and a group respectively, and a clause complex congruently realizes a sequence. But a clause and even a group, in which grammatical metaphor is involved, as it expands the semantic potential of the system, may alternatively realize a sequence. The ideational metaphor reflects a shift from sequence to figure, or from figure to participant, and thus falls into the ideational function, as its primary effect is ideational. Halliday and Matthiessen summarize experiential meaning and its realization as follows in Table 2.

Table 2

Congruent Form and Metaphorical Form of Experiential Meaning in Lexicogrammar

\begin{tabular}{|c|c|c|c|c|}
\hline \multicolumn{3}{|l|}{ Congruent form } & \multicolumn{2}{|l|}{ Metaphorical form } \\
\hline Ranks of experiential meaning & $\mathrm{FI}$ & & Ranks of experiential meaning & FRL \\
\hline Sequence & $\longrightarrow$ & Clause complex & Figure & $\rightarrow$ Clause \\
\hline Figure & $\longrightarrow$ & Clause & $\begin{array}{c}\text { Element: participant: attribute } \\
\text { and process }\end{array}$ & $\rightarrow$ Group/phrase \\
\hline $\begin{array}{l}\text { Element: participant: attribute } \\
\text { and process }\end{array}$ & $\longrightarrow$ & Group/phrase & Element: participant: thing & $\rightarrow$ Group/phrase \\
\hline
\end{tabular}

Notes. In this table, FRL signifies the forms in which the ranks of experiential meaning are realized in lexicogrammar.

From Table 2, we can find that one of the important functions of ideational metaphors is to make experiential meaning abstract, which is mainly realized in lexicogrammar by nominalization. In other words, an experiential figure which is usually realized by a clause in other genres like novels is realized metaphorically as an element (participant: thing) realized by a nominal group, as is shown in (1)a; or an experiential figure or sequence which is usually realized by a nominal group plus an embedded clause or clause complex in other genres is realized metaphorically as an experiential element realized by a nominal phrase, like the case in (2)a.

(1) a. This paper presents a comparison of some features for speaker identification applied to a building security system (LI, 2005).

b. This paper presents a comparison of some features, which can be applied to a building security system to identify speakers.

(2) a. How quickly such memories fade from the public memories will depend on many unknowables (LI, 2005).

b. How quickly such memories fade from the public memories will depend on many factors, which are unknowable.

In a word, scientific texts, by a series of concepts, propositions, etc., are aimed at making scientific achievements known, popularizing inventions and creations, as well as diffusing scientific and technical knowledge. Therefore, the authors of EST texts usually transfer attributes and processes into nominal groups with higher information density to express more abstract and complicated experience as well as higher level of cognition. In the following, an analysis will be carried out from five perspectives of the reasons for the use of experiential metaphor, primarily nominalization and adjectivization, in EST texts. 
(1) Both nominalization and adjectivization reduce overt processes and thus render the scientific discourse more like an object, that is, the disguising of overt process.

(2) Use ideational metaphors to nominalize actions, give things existence, and make things act and employ identifying relational processes. As a result, the knowledge is objectified and the texts are rendered system-like rather, creating the special texture of EST texts.

(3) By nominalizing this way, we are achieving two important discoursal effects:

a. Packaging a complex phenomenon into a single semiotic entity, by making it one element of clause structure;

b. Its rhetorical function - the tool of textual organization by unfolding the thematic and information structures of a text-is rendering the whole text cohesive and well-organized.

Just as Thompson puts it, "one important function of nominalization is encapsulation" (Thompson, 2000, p. 170). Broadly speaking, cooperative text typically introduces new meanings in the form of clauses, since clauses are negotiable: They represent claims by the writer, which the reader can, in principle, reject. Once a meaning has been introduced in this way and has been accepted (i.e., the reader has continued reading), it can then be used as a basis for the next step in the argument. Now, nominal groups have two qualities, which are useful here. First, a noun typically refers to a "thing", i.e., something that exists. By "nominalizing" a process, the writer can reflect the fact that $\mathrm{s} / \mathrm{he}$ has negotiated and established the meaning of the clause centered around the process - in other words, that meaning can now be treated as existing, as a kind of abstract "thing". Second, a nominalization is itself available to function as a participant in another process. It can also, of course, function as Theme. We therefore find the fairly common pattern in EST texts where a meaning is brought in as a full clause, and is then encapsulated in a nominalization, which serves as the starting point for the next clause. Third, nominalization can be used to encapsulate a concept which has been established clausally a couple of sentences previously. Therefore, the technical term can be seen as a "condensation" of the clause, such as genetic-screening in genetic-screening approach and carbon-bearing in carbon-bearing pellets. Besides, another reason why nominalization is in harmony with the ideology of academic, formal writing in general, science in particular is that it allows processes to be objectified, to be expressed without the human doer. This objectification is often carried over into the verbs that express the process. Nominalized meanings may, for example, "indicate" conclusions (to whom?):

Here, a statistical analysis of the actual vote indicates that opposition was localized.

At the same time, nominalized processes are non-finite: They are not tied to any specific time in relation to the time of speaking. (Incidentally, this is yet another reflection of the functional unity of Mood: Both Subject and Finite typically disappear when a process is nominalized.) Thus a nominalized process is detached from the here-and-now in a way that is not normally possible for a process expressed by a verb. It is therefore inherently generalized-again, in harmony with the aim of science to establish general truths not tied to specific conditions of time or observer (ibid.). If we go a step further, we can see that, by removing the option of a Mood, a nominalized process has been made non-negotiable. This is intimately connected with the fact that it is also "thingfied" by being expressed as a noun. Science aims to establish not only general truths, but also unassailable, certain truths. Our current ideology of science is far happier with a view of the world as a series of fixed constants acting on each other in logically definable ways. In linguistic terms, this is reflected in, and reinforced by, the preference for nominalizations, which represent "fossilized" processes, and verbs whose primary function is to express not dynamic action but relationships between the nominals. 


\section{Conclusion}

According to the results from the statistical analysis of the distribution of 13 types of GM in 20 EST texts chosen at random, it is indicated that Halliday-Martin's claim is right, namely, in EST texts what is called GM is primarily nominalization. By packing a simple clause into a phrase or two or three clauses into one clause, nominalization can help EST texts express more complicated experience and higher level of cognition. On the other hand, nominalization reduces overt processes and thus renders the scientific discourse more like an object and at the same time achieves the effect of being concise by packing processes into things. A nominalization is itself available to function as a participant in another process. It can function as theme. In EST texts, a meaning is usually brought in as a full clause, and is then encapsulated in a nominalization, which serves as the starting-point for the next clause. Therefore, in EST texts, nominalization generally performs a powerful cohesive function. Another reason for a preference for nominalization in EST texts is that this device allows us to utilize the full grammatical resources available to things in English.

This study, on the one hand, can help us with a better understanding and command of the characteristics of EST texts and in turn bring benefit to language teaching, especially EST teaching, such as EST reading, writing and translation, and on the other hand, can shed new light on the nature of language of science and technology, language as a whole, and help us with a more solid prediction of the trend of language development and even the law of human cognitive development.

\section{References}

Bloor, T., \& Bloor, M. (1995). The functional analysis of English: A Hallidayan approach. London: Arnold.

Fan, W. F. (2001). The theoretical study on grammatical metaphor. Peking: Foreign Language Teaching \& Research Press.

Halliday, M. A. K. (1973). Explorations in the functions of language. London: Edward Arnold.

Halliday, M. A. K. (1994). An introduction to functional grammar. London: Edward Arnold.

Halliday, M. A. K. (1996). Reading science: Critical and functional perspectives on discourses of science. London: Edward Arnold.

$\mathrm{Hu}$, Z. L. (1990). The system and function of language. Peking: Peking University Press.

Lakoff, G., \& Johnson, M. (1980). Metaphors we live by. Chicago: University of Chicago University Press.

Langacker, R. W. (1987). Foundations of cognitive grammar. Stanford: Stanford University Press.

Li, Y-G. (2005). Explorations into grammatical metaphors in EST texts (Master dissertation, Shandong University, Shandong).

Martin, J. R. (1987). New developments in systemic linguistics. New York: Frances Pinter Publishers.

Martin, J. R. (1992). English text: System and structure. Amsterdam: John Benjamin's Pub. Co..

Nuttal, C. (1982). Teaching reading skills in a foreign language. London: Heinemann Educational Books.

Thompson, G. (1996). Introducing functional grammar. London: Edward Arnold limited.

Thompson, G. (2000). Introduction to functional grammar. Beijing: Foreign Language Teaching and Research Press.

Thornley, G. C. (1977). Elementary scientific English practice. London: Longman Group. 